
Kidney
Blood Pressure
Research

Kidney Blood Press Res 2015;40:207-214

DOI: $10.1159 / 000368496$

Published online: April 10, 2015

(c) 2015 S. Karger AG, Basel

www.karger.com/kbr

Accepted: March 03, 2015

1423-0143/15/0403-0207\$39.50/0

This is an Open Access article licensed under the terms of the Creative Commons AttributionNonCommercial 3.0 Unported license (CC BY-NC) (www.karger.com/OA-license), applicable to the online version of the article only. Distribution permitted for non-commercial purposes only.

\title{
Continuous Lead Exposure Increases Blood Pressure but Does Not Alter Kidney Function in Adults 20-44 Years of Age in a Lead-Polluted Region of China
}

\author{
Yao Lu ${ }^{a}$ Xing Liu ${ }^{a}$ Qihong Deng ${ }^{b}$ Yizhu Duan ${ }^{a}$ Haijiang Daia Ying Li $^{a}$ \\ Ting Xiao ${ }^{a}$ Xingping Ning ${ }^{c}$ Jialun Fan ${ }^{c}$ Li Zhou $^{d}$ Xiaohui Lia \\ Hua Zhong ${ }^{\text {a Hong Yuan }}{ }^{a}$
}

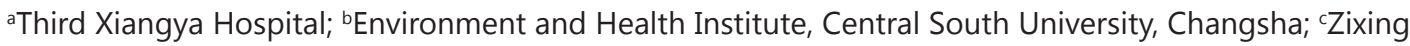
Centers for Disease Control and Prevention; 'Zixing Environmental Monitoring Center, Zixing, China

\section{Key Words}

Lead $•$ Chronic saturnism $•$ Blood pressure $\cdot$ Hypertension $•$ Kidney function $•$ Continuous lead pollution

\begin{abstract}
Background/Aims: To examine the relationships among blood lead levels, blood pressure and kidney function in a population-based sample of adults in an area of China with lead pollution. Methods: This cross-sectional study included a sample of 1447 adults older than 20 years of age who underwent physical examinations in hospitals within a lead-polluted area of China from January to December 2013. Results: Blood lead levels were high among the local population $(152.47 \mu \mathrm{g} / \mathrm{L})$ and did not change with age $(P=.182)$. Overall, changes in both systolic blood pressure (SBP) and diastolic blood Pressure (DBP) were associated with changes in blood lead level $(P=.012, P=.001)$, whereas BUN and $C C r$ did not change along with the blood lead level $(P>.05)$. This relationship was strongest among people 20-45 years of age; in this group, the beta coefficients for SBP and DBP were 0.009 (0.003), $P=.001$ and 0.005 (0.002), $\mathrm{P}=.004$, respectively. Compared with young men, young women's blood pressures were more affected by blood lead levels (beta for $\mathrm{SBP}=0.031$ for women vs. 0.008 for men; beta for $\mathrm{DBP}=0.015$ for women vs. 0.005 for men). Conclusion: Continuous lead exposure causes increased blood lead levels among local residents. Blood lead levels are positively associated with both SBP and DBP increases among adults aged 20-44 years. The relationships between blood lead levels and SBP and DBP are most pronounced in young women. Chronic saturnism does not increase blood pressure by altering kidney function. These results provide support for continued efforts to control blood pressure in the population living in a lead-polluted region of China, particularly in young women.
\end{abstract}




\section{Kidney \\ Blood Pressure Research}

Kidney Blood Press Res 2015;40:207-214

\begin{tabular}{l|l}
\hline DOI: $10.1159 / 000368496$ & (C) 2015 S. Karger AG, Basel
\end{tabular}

Published online: April 10, 2015

www.karger.com/kbr

Lu/Liu/Deng/Duan/Dai/Li/Xiao/Ning/Fan/Zhou/Li/Zhong/Yuan: Lead Exposure Increases Blood Pressure

\section{Introduction}

High blood pressure and lead exposure are the second and fifteenth leading risk factors affecting disability-adjusted life-years (DALYs) in China (Lancet, 2013) [1], which indicates that both high blood pressure and lead exposure are important health risk factors for Chinese people. Lead acts at multiple sites within the cardiovascular system; it exerts direct effects on the excitability and contractility of the heart, alters the compliance of vascular smooth muscle tissue and acts directly on the parts of the central nervous system responsible for blood pressure regulation [2, 3]. Animal research and studies involving the general populations have also shown that exposure to lead may impair renal function [4]. Considerable attention has been paid to different levels of acute lead exposure in the general population, as excessive lead exposure may increase the risk of both hypertension and kidney damage [5-7]. However, the relationships among blood lead levels, blood pressure and kidney function remain controversial. Whether lead changes blood pressure (BP) by impairing kidney function or via another mechanism remains unknown.

With the rapid industrial development that has occurred in China over the past 20 years, lead pollution has become an important problem. Due to its extensive industrial use [8], lead continues to be released into the environment, and given that lead cannot be degraded, it contaminates the earth's crust and drinking water. Thus, it is important that researchers study and understand the consequences of chronic saturnism, and particularly the relationships among lead exposure, hypertension and kidney function, in people.

The objective of our investigation was to examine the relationships among blood lead levels, blood pressure and kidney function in a population-based sample of adults with chronic saturnism who live in a region of China with lead pollution. We selected blood pressure, hypertension, blood urea nitrogen (BUN) and creatinine clearance (CCr) as the outcome parameters of interest for our study, because hypertension and kidney disease are both significant health concerns among Chinese adults and because we could also determine whether lead exposure alters kidney function before it facilitates increases in BP.

\section{Materials and Methods}

The study protocol was approved by the Medical Ethics Committee of the Third Xiang-ya Hospital. Each of the subjects enrolled in this study provided informed consent to participate.

\section{Study design and population}

Zixing is located in southern China and is famous for its coal mining and silver mining. As a consequence of several decades of mining, significant amounts of lead have been released into the environment, causing a increasing of blood lead level among the area's local residents. Within the past 10 years, there has been a string of lead poisoning outbreaks. In this cross-sectional study, 3000 Chinese people living in Zixing underwent an annual physical examination at the Centers for Disease Control (CDC) in Zixing.

The study's inclusion criteria were as follows: age $\geq 20$ years old and either male or female gender. Exclusion criteria included the following: 1) the absence of data pertaining to age, gender, BP, blood lead levels, BUN, serum creatinine (Scr) levels, urine analysis, body weight, or height; 2) a history of cardiovascular or renal disease; and 3) duplicate cases. A total of 1447 subjects who met the inclusion criteria were eligible for inclusion in this study. Hypertension was defined according to the JNC 7 Report [9], and individuals who had previously received a diagnosis of hypertension were also considered to have hypertension. At the baseline we divided the participants into 2 groups by blood lead level: $<100 \mu \mathrm{g} / \mathrm{L}$ and $\geq 100 \mu \mathrm{g} / \mathrm{L}$ [10]. Then we divided the participants into the following 3 groups by age: age 20-39 years, age 40-59 years, and age $>60$ years (WHO) [11]. Body mass index (BMI) and heart rate were measured because their great influence on blood pressure and kidney function $[12,13]$.

Air lead concentration data was collected by the Environmental and Health Institute of Central South University. 


\section{Kidney \\ Blood Pressure Research}

Kidney Blood Press Res 2015;40:207-214

\begin{tabular}{l|l}
\hline DOI: $10.1159 / 000368496$ & (C) 2015 S. Karger AG, Basel
\end{tabular}

Published online: April 10, 2015

www.karger.com/kbr

Lu/Liu/Deng/Duan/Dai/Li/Xiao/Ning/Fan/Zhou/Li/Zhong/Yuan: Lead Exposure Increases Blood Pressure

Blood lead measurements

Blood samples were obtained by venipuncture during the physical examination. The blood lead concentration was measured via graphite furnace atomic absorption spectrophotometry at the laboratories of the Zixing CDC. Each sample was analyzed in duplicate, and the mean of both measurements was used for subsequent analyses.

\section{Blood pressure measurements}

All participants rested for at least $30 \mathrm{~min}$, after which their blood pressures were measured twice in their right arms using a desk-model sphygmomanometer while the participants were in a sitting position. There was a 3-min interval between the two measurements for each participant, and the mean value of the two measurements was used for subsequent analyses.

\section{Anthropometric measurements}

Height and weight were measured in meters by the G-TECH Company. All individuals were measured while wearing scrubs. Height was measured to the nearest $0.1 \mathrm{~cm}$ using a tape rule, and weight was measured to the nearest $0.1 \mathrm{~kg}$ using a calibrated platform scale. Each participant's body mass index (BMI) was calculated as the participant's body weight $(\mathrm{kg})$ divided by the square of the participant's height $\left(\mathrm{m}^{2}\right)$.

\section{Kidney function}

CCr was used as indicator of kidney function based on the following equation: $\mathrm{CCr}=(140 \text {-age })^{*}$ weight/ $(72 * \mathrm{Scr})$ for male and $\mathrm{CCr}=0.85 *(140 \text {-age })^{*}$ weight $/(72 * \mathrm{Scr})$ for female. In order to measure Scr, blood was collected via venipuncture following an overnight fast of at least $10 \mathrm{~h}$. Serum creatinine was measured using Jaffe's kinetic method. Serum BUN was determined using a commericial kit according to manufacturer's instructions.

\section{Statistical analyses}

The data were analyzed using SPSS17.0. T-test was used to evaluate P values between groups of two blood lead level. The Kruskal-Wallis test was used to evaluate P values among the 3 groups of age. The chisquared test was used to compare the occurrences of hypertension. Linear regression was used to compare the relationships among SBP, DBP, BUN, CCr and blood lead levels. Logistic regression was used to compare the relationship between hypertension and blood lead levels. We used the Pearson correlation coefficient for continuous variables and Spearman correlation coefficients for dichotomous variables. Statistical significance was set at $\mathrm{P}<.05$.

\section{Results}

\section{Summary of the participants}

The study included 1447 participants who live in a region of China with heavy metal pollution; in this region, the mean concentration of lead in the air is $546.93 \mathrm{ug} / \mathrm{m}^{3}$. The participants' mean age was 46.68 years, and their mean blood lead concentration was 152.47 $\mu \mathrm{g} / \mathrm{L}$. The average BMI was 23.24. The means of systolic and diastolic blood pressure were 124.61 and $79.82 \mathrm{mmHg}$, respectively, and approximately $15.4 \%$ of the participants met the definition of hypertension. The average BUN and CCr were $4.47 \mathrm{mmol} / \mathrm{L}$ and $76.78 \mathrm{~mL} / \mathrm{min}$ (Table 1). There were significant differences in age, BMI, SBP, DBP, CCr and hypertension occurrence between low blood lead level group and high blood lead level group ( $<<.05)$.

No significant difference was found among the blood lead concentrations of the different age groups included in this study $(\mathrm{P}=.182)$. Significant differences in $\mathrm{BMI}$, heart rate, SBP, DBP, hypertension occurrence and CCr were found among the different age groups $(\mathrm{P}<.01)$, (Table 2).

The relationships between blood lead levels and $B P, B U N$ and $C C r$

The relationships between blood lead levels and SBP and DBP in the study population as a whole were found to be significant after adjusting for age, BMI, heart rate and gender, 


\section{Kidney \\ Blood Pressure Research}

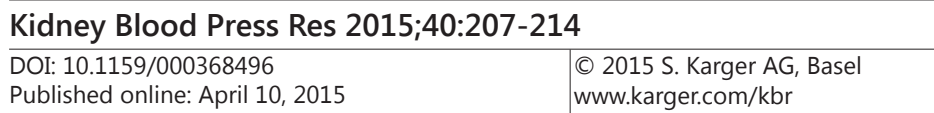

Lu/Liu/Deng/Duan/Dai/Li/Xiao/Ning/Fan/Zhou/Li/Zhong/Yuan: Lead Exposure Increases Blood Pressure

Table 1. Characteristics of the study participants, overall and by blood lead levels

\begin{tabular}{lcccc}
\hline Characteristic & $\begin{array}{c}\text { Total } \\
\mathrm{N}=1447\end{array}$ & $\begin{array}{c}\text { Blood lead level } \\
(0-100 \text { ug/L) } \\
\mathrm{N}=669\end{array}$ & $\begin{array}{c}\text { Blood lead level } \\
(\geq 100 \mathrm{ug} / \mathrm{L}) \\
\mathrm{N}=778\end{array}$ & $\begin{array}{c}\text { P-value } \\
\text { Concentration of lead in the air, mean (SD), ug/m3 }\end{array}$ \\
Blood lead concentration, mean (SD), ug/L & $152.47(150.68)$ & $63.42(20.98)$ & $229.03(170.82)$ & $<.001$ \\
Age, mean (SD), y & $46.68(15.13)$ & $44.72(14.70)$ & $48.36(15.30)$ & $<.001$ \\
BMI, mean (SD) & $23.24(0.08)$ & $22.84(2.97)$ & $23.59(3.32)$ & $<.001$ \\
Heart rate, mean (SD) & $71.08(3.18)$ & $71.30(10.04)$ & $70.89(10.23)$ & .437 \\
SBP, mean (SD), mmHg & $124.61(17.25)$ & $121.92(17.05)$ & $126.93(17.09)$ & $<.001$ \\
DBP, mean (SD), mmHg & $79.82(9.74)$ & $89.85(13.36)$ & $95.09(63.18)$ & $<.001$ \\
Hypertension, \% & 15.41 & 12.26 & 18.12 & .002 \\
BUN, mean (SD), mmol/L & $4.47(3.49)$ & $4.42(2.92)$ & $4.52(3.91)$ & .583 \\
CCR, mean (SD), ml/min & $76.78(70.44)$ & $73.06(31.92)$ & $79.96(91.30)$ & .063 \\
\hline
\end{tabular}

Note: T-test was used to evaluate the P-values between the 2 groups. The chi-squared test was used to compare the occurrences of hypertension

Table 2. Weighted Descriptive Characteristics, by age

\begin{tabular}{lcccc}
\hline Characteristic & $20-44$ & $45-59$ & $\geq 60$ & P-value \\
& $\mathrm{N}=758$ & $\mathrm{~N}=417$ & $\mathrm{~N}=272$ & \\
\hline Blood lead concentration, mean (SD), ug/L & $162.78(173.63)$ & $152.33(144.81)$ & $123.95(60.23)$ & .182 \\
Age, mean (SD), y & $35.87(6.48)$ & $49.50(4.23)$ & $72.47(8.36)$ & $<.001$ \\
BMI, mean (SD) & $22.87(3.16)$ & $23.79(2.91)$ & $23.43(3.48)$ & $<.001$ \\
Heart rate, mean (SD) & $70.75(10.12)$ & $70.61(9.51)$ & $72.74(10.97)$ & .002 \\
SBP, mean (SD), mmHg & $118.06(13.20)$ & $126.55(15.06)$ & $139.90(19.80)$ & $<.001$ \\
DBP, mean (SD), mmHg & $78.59(9.04)$ & $81.27(10.28)$ & $81.01(10.31)$ & $<.001$ \\
Hypertension, \% & 9.89 & 20.62 & 22.79 & $<.001$ \\
BUN, mean (SD), mmol/L & $4.27(2.38)$ & $4.57(4.26)$ & $4.91(4.57)$ & 0.026 \\
CCr, mean (SD), ml/min & $85.58(37.15)$ & $79.94(177.72)$ & $47.39(15.74)$ & $<0.001$ \\
\hline
\end{tabular}

Note: The Kruskal-Wallis test was used to evaluate the P-values among the 3 groups. The chi-squared test was used to compare the occurrences of hypertension

using multiple linear regression analysis, and the relationship between blood lead levels and BUN and CCr were insignificant. The result of the logistic regression model indicates that the occurrence of hypertension was not related to blood lead levels (Table 3).

The relationships between blood lead levels and $B P, B U N$ and $C C r$, stratified by age

The results of multiple linear regression analysis of the relationships between blood lead levels and BP, BUN and CCr for each age group, considered separately, appear in Table 4. After adjusting for age gender, BMI, and heart rate, the relationships between blood lead levels and SBP and DBP remained significant for individuals aged 20-44 years, as was the relationship between blood lead levels and DBP in individuals over the age of 60 years. BUN and CCr were not related to blood lead levels.

Regression coefficients for blood lead levels, SBP and DBP for individuals aged 20-44 years, stratified by gender

In individuals aged 20-44 years stratified by gender, the adjusted beta coefficients for levels as a function of SBP in females were 0.031 and 0.015 , respectively; these values were much higher than the corresponding beta coefficients for males (Table 5). These results indicated that the relationship between blood lead levels and blood pressure was much stronger in females than in males.

\section{Discussion}

Our cross-sectional investigation determined that continuous lead pollution in the environment caused high blood lead levels in local residents and that these high levels did not vary with age. No significant relationship was found between blood lead levels and hyper- 


\section{Kidney \\ Blood Pressure Research}

Kidney Blood Press Res 2015;40:207-214

DOI: 10.1159/000368496

Published online: April 10, 2015

C 2015 S. Karger AG, Basel

www.karger.com/kbr

Lu/Liu/Deng/Duan/Dai/Li/Xiao/Ning/Fan/Zhou/Li/Zhong/Yuan: Lead Exposure

Increases Blood Pressure

tension. Chronic saturnism does not lead directly to kidney damage, which indicates that lead does not affect blood pressure by altering kidney function. However, blood lead levels were positively associated with both SBP and DBP increases among adults aged 20-45 years. The relationships between blood lead levels, both SBP and DBP were most pronounced in young women.

\section{Blood lead levels}

Previous reports have shown that bone lead stores contribute to circulating levels of lead in the blood [11], suggesting that blood lead levels may be higher in the elderly than in young people. Research based on the populations of countries such as the USA has confirmed that blood lead levels change with age in environments with limited lead pollution [14]. A study in Korea demonstrated

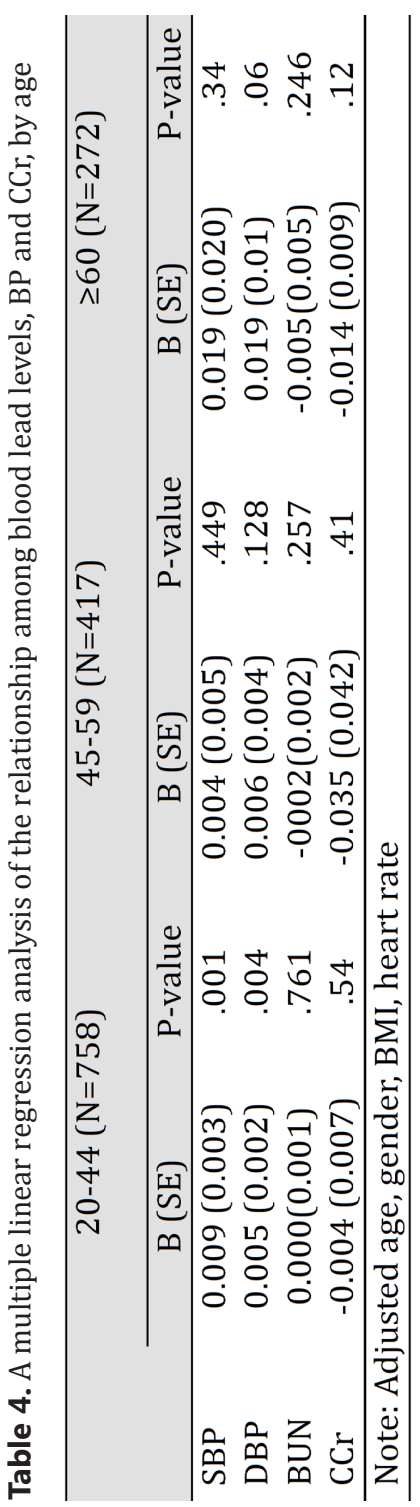
that blood lead concentrations increased with age; the highest concentrations were found in the 50-69 years age group, and males had higher levels than females [15]. Significant efforts have also been made to promote improved healthcare practices in working populations [16, 17]. However, no research published to date has focused on the blood lead levels of residents in a lead-polluted region. In our study, we conducted a survey of a lead-polluted area in China, and we found that in a region characterized by continuous lead pollution, blood lead levels in the local population were elevated and that no difference existed in the mean blood lead levels among the different age groups included in our study. Future efforts should focus on both children and the elderly living in this area, in addition to young adults.

\section{$S B P \& D B P$}

The relationship between blood pressure and blood lead levels has been investigated by both basic science researchers and cli- 


\section{Kidney \\ Blood Pressure Research}

Kidney Blood Press Res 2015;40:207-214

\begin{tabular}{l|l}
\hline DOI: $10.1159 / 000368496$ & (c) 2015 S. Karger AG, Basel
\end{tabular}

Published online: April 10, 2015

www.karger.com/kbr

Table 5. Regression coefficients for blood lead levels, SBP and DBP for individuals aged 20-44 years, stratified by gender

\begin{tabular}{lcccc}
\hline & \multicolumn{2}{c}{ Male (N=471) } & \multicolumn{2}{c}{ Female (N=287) } \\
\cline { 2 - 5 } & B (SE) & P-value & B (SE) & P-value \\
\cline { 2 - 5 } SBP, Regression coefficients (SE) & & & & \\
Blood lead level & $0.008(0.003)$ & .003 & $0.031(0.010)$ & .002 \\
Age, y & $0.079(0.081)$ & .331 & $0.370(0.130)$ & .005 \\
Heart rate & $0.151(0.054)$ & .006 & $0.173(0.073)$ & .018 \\
BMI & $0.931(0.162)$ & $<.001$ & $1.347(0.296)$ & $<.001$ \\
DBP, Regression coefficients (SE) & & & & \\
Blood lead level & $0.005(0.002)$ & .018 & $0.015(0.006)$ & .017 \\
Age, y & $0.092(0.061)$ & .133 & $-0.050(0.083)$ & .547 \\
Heart rate & $0.127(0.041)$ & .002 & $0.076(0.047)$ & .105 \\
BMI & $0.489(0.121)$ & $<.001$ & $0.824(0.189)$ & $<.001$ \\
\hline Note: Linear regression & & & & \\
\hline
\end{tabular}

nical researchers for decades. Most basic researchers used models of short-term lead exposure [7] or models of a single acute exposure [18] to determine how lead exposure changes blood pressure. Studies conducted by clinical researchers have primarily examined populations in non-lead-polluted areas $[19,20]$ or focused on a special population, but these studies did not reach a definitive conclusion regarding the relationship between lead levels and blood pressure.

Our study confirmed the existence of significant linear relationships between blood lead levels and SBP and DBP in a population living in a lead-polluted region after adjusting for age, gender, BMI and heart rate and thus provided an improved estimate of the effect of blood lead levels on SBP and DBP. Based on this finding, we investigated whether differences in this relationship existed among different age groups; we found that the blood lead concentrations affect both SBP and DBP among adults aged 20-44 years, particularly among women in this age group. These results are different from the results of other studies. The reason for this relationship is unclear. Children are the most susceptible to lead exposure and the lead pollution in Zixing is only several decades in duration. Thus the group of adults 2044 years of age would be the only study participants exposed to lead pollution as children. The adults now older that 44 years of age were not exposed to the lead pollution as children and therefore their blood pressure is not as affected as the 20-44 age group.

Several other epidemiological studies have been conducted over the past 20 years, but the results of these studies have been mixed, according to data from a national survey conducted in both the USA and Canada [20,21]. In an environment characterized by continuous lead pollution, lead may enter the human body through the skin, respiratory tract and digestive tract $[22,23]$. The effect of continuous lead intake may differ from the effect of acute lead exposure or lead accumulation as a result of advanced age. The present study has provided strategies for the management of blood pressure for populations living in such an environment.

\section{Hypertension \& kidney function}

The mechanisms underlying the effect of lead on BP have not been elucidated. Lead is toxic to humans and alterations in kidney function as a result of lead exposure may precede the development of hypertension [24, 25]. Whether lead affects blood pressure by altering kidney function in humans is not known. Some researchers believe that lead exposure effects angiotensin II-induced renal vasoconstriction [26], whereas others believe that lead-induced hypertension may be related to decreased NO levels and to subsequent vasoconstriction, rather than decreased renal blood flow or decreased renal sodium [27]. In our study, kidney 


\section{Kidney \\ Blood Pressure Research}

Kidney Blood Press Res 2015;40:207-214

\begin{tabular}{l|l}
\hline DOI: $10.1159 / 000368496$ & (C) 2015 S. Karger AG, Basel
\end{tabular}

Published online: April 10, 2015

www.karger.com/kbr

Lu/Liu/Deng/Duan/Dai/Li/Xiao/Ning/Fan/Zhou/Li/Zhong/Yuan: Lead Exposure Increases Blood Pressure

function as measured by BUN and CCr did not appear to play a role in the relationship between blood lead levels and blood pressure. CCr reflects the glomerular filtration rate and is frequently used to measure renal function because of its simplicity and adjustment for age and gender [28]. The results of the present study indicate that lead does not damage the kidneys directly, as it increases BP simultaneously, which indicates that lead changes BP by a means other than the alteration of kidney function. Future research should focus on the effect that lead exerts on the vascular system and the nervous system, particularly in young adults with a history of continuous lead exposure.

\section{Conclusion}

Continuous lead pollution in the environment causes high blood lead levels among local residents. Blood lead levels are positively associated with both SBP and DBP increases among adults aged 20-44 years. The correlations of blood lead level and SBP and DBP are most pronounced in young women. Chronic saturnism does not affect BP by impairing kidney function. These results provide support for the undertaking of continued efforts to control BP levels in populations exposed to lead, particularly among young women. Further research must be conducted regarding the mechanisms underlying lead exposure-induced changes in BP.

\section{Disclosure Statement}

The authors of this manuscript state that they do not have any conflict of interests and nothing to disclose.

\section{Acknowledgments}

The authors report no conflicts of interest. The authors are grateful for the help provided by Professor Xiang Chen. This research was supported by grants from the National Natural Science Foundation of China (No. 81273594), the National Key Technology R\&D Program (No.2012BAI37B05) and the Huimin Projects of Science and Technology (2012GS430101).

\section{References}

1 Yang G, Wang Y, Zeng Y, Gao GF, Liang X, Zhou M, Wan X, Yu S, Jiang Y, Naghavi M, Vos T, Wang H, Lopez AD, Murray CJ: Rapid health transition in China, 1990-2010: findings from the Global Burden of Disease Study 2010. Lancet 2013;381:1987-2015.

2 Nash D, Magder L, Lustberg M, Sherwin RW, Rubin RJ, Kaufmann RB, Silbergeld EK: Blood lead, blood pressure, and hypertension in perimenopausal and postmenopausal women. JAMA 2003;289:1523-1532.

3 Kopp SJ, Barron JT, Tow JP: Cardiovascular actions of lead and relationship to hypertension: a review. Environ Health Perspect 1988;78:91-99.

4 Staessen JA, Lauwerys RR, Buchet JP, Bulpitt CJ, Rondia D, Vanrenterghem Y, Amery A: Impairment of renal function with increasing blood lead concentrations in the general population. The Cadmibel Study Group. N Engl J Med 1992;327:151-156.

5 Rossignol P, Kessler M, Zannad F: Visit-to-visit blood pressure variability and risk for progression of cardiovascular and renal diseases. Curr Opin Nephrol Hypertens 2013;22:59-64.

6 Vaziri ND: Pathogenesis of lead-induced hypertension: role of oxidative stress. J Hypertens 2002;20:S15-S20.

7 Fioresi M, Simões MR, Furieri LB, Broseghini-Filho GB, Vescovi MV, Stefanon I, Vassallo DV: Chronic lead exposure increases blood pressure and myocardial contractility in rats. PloS one 2014; 9:e96900. 


\section{Kidney \\ Blood Pressure Research}

Kidney Blood Press Res 2015;40:207-214

\begin{tabular}{l|l}
\hline DOI: $10.1159 / 000368496$ & (C) 2015 S. Karger AG, Basel
\end{tabular}

Published online: April 10, 2015

www.karger.com/kbr

8 Abadin H, Ashizawa A, Stevens YW, Llados F, Diamond G, Sage G, Citra M, Quinones A, Bosch SJ, Swarts SG: Toxicological profile for lead. US Department of Health and Human Services, Public Health Service Agency for Toxic Substances and Disease Registry, 2007.

9 Chobanian AV, Bakris GL, Black HR, Cushman WC, Green LA, Izzo JL Jr, Jones DW, Materson BJ, Oparil S, Wright JT Jr, Roccella EJ; National Heart, Lung, and Blood Institute Joint National Committee on Prevention, Detection, Evaluation, and Treatment of High Blood Pressure; National High Blood Pressure Education Program Coordinating Committee: The Seventh Report of the Joint National Committee on Prevention, Detection, Evaluation, and Treatment of High Blood Pressure: the JNC 7 report. JAMA 2003;289:2560-2572.

10 Centers for Disease Control (US): Preventing lead poisoning in young children: a statement. The Centers, 1991.

11 Symanski E, Hertz-Picciotto I: Blood lead levels in relation to menopause, smoking, and pregnancy history. Am J Epidemiol 1995;141:1047-1058.

12 Liu Q, Li Z, Wang H, Chen X, Dong X, Mao H, Tan J, Luo N, Johnson RJ, Chen W, Yu X, Chen W: High prevalence and associated risk factors for impaired renal function and urinary abnormalities in a rural adult population from southern China. PloS one 2012;7:e47100.

13 Brotman DJ, Bash LD, Qayyum R, Crews D, Whitsel EA, Astor BC, Coresh J: Heart rate variability predicts ESRD and CKD-related hospitalization. J Am Soci Nephrol 2010;21:1560-1570.

14 Rosin A: The long-term consequences of exposure to lead. Isr Med Assoc J 2009;11:689-694.

15 Jeong SW, Lee CK, Suh CH, Kim KH, Son BC, Kim JH, Lee JT, Lee SW, Park YB, Lee JW, Yu SD, Moon CS, Kim DH, Lee SY: Blood lead concentration and related factors in Korea from the 2008 National Survey for Environmental Pollutants in the Human Body. Int J Hyg Environ Health 2014;217:871-877.

16 Poręba R, Gać P, Poręba M, Andrzejak R: Environmental and occupational exposure to lead as a potential risk factor for cardiovascular disease. Environ Toxicol Pharmacol 2011;31:267-277.

17 Xuezhi J, Youxin L, Yilan W: Studies of lead exposure on reproductive system: a review of work in China. Biomed Environ Sci 1992;5:266-275.

18 Simões MR1, Ribeiro Júnior RF, Vescovi MV, de Jesus HC, Padilha AS, Stefanon I, Vassallo DV, Salaices M, Fioresi M: Acute lead exposure increases arterial pressure: role of the renin-angiotensin system. PloS one 2011;6:e18730.

19 Faramawi MF, Delongchamp R, Lin YS, Liu Y, Abouelenien S, Fischbach L, Jadhav S: Environmental lead exposure is associated with visit-tovisit systolic blood pressure variability in the US adults. Int Arch Occup Environ Health 2015;88:381-388.

20 Hara A, Thijs L, Asayama K, Gu YM, Jacobs L, Zhang ZY, Liu YP, Nawrot TS, Staessen JA: Blood pressure in relation to environmental lead exposure in the national health and nutrition examination survey 2003 to 2010. Hypertension 2015;65:62-69.

21 Bushnik T, Levallois P, D‘Amour M, Anderson TJ, McAlister FA: Association between blood lead and blood pressure: Results from the Canadian Health Measures Survey (2007 to 2011). Health Rep 2014;25:12-22.

22 Rahman MA, Rahman MM, Reichman SM, Lim RP, Naidu R: Heavy metals in Australian grown and imported rice and vegetables on sale in Australia: Health hazard. Ecotoxicol Environ Saf 2014;100:53-60.

23 Untimanon O, Geater A, Chongsuvivatwong V, Saetia W, Utapan S: Skin lead contamination of family members of boatcaulkers in southern Thailand. Ind Health 2011;49:37-46.

24 Batuman V, Landy E, Maesaka JK, Wedeen RP: Contribution of lead to hypertension with renal impairment. N Engl J Med 1983;309:17-21.

25 Kim R, Rotnitzky A, Sparrow D, Weiss S, Wager C, Hu H: A longitudinal study of low-level lead exposure and impairment of renal function: the Normative Aging Study. JAMA 1996;275:1177-1181.

26 Robles HV, Romo E, Sanchez-Mendoza A, Rios A, Soto V, Avila-Casado MC, Medina A, Escalante B: Lead exposure effect on angiotensin II renal vasoconstriction. Hum Exp Toxicol 2007;26:499-507.

27 Dursun N, Arifoglu C, Süer C, Keskinol L: Blood pressure relationship to nitric oxide, lipid peroxidation, renal function, and renal blood flow in rats exposed to low lead levels. Biol Trace Elem Res 2005;104:141149.

28 Kuroda T, Tanabe N, Kobayashi D, Wada Y, Murakami S, Nakano M, Narita I: Significant association between renal function and amyloid-positive area in renal biopsy specimens in AL amyloidosis. BMC Nephrol 2012;13:118. 